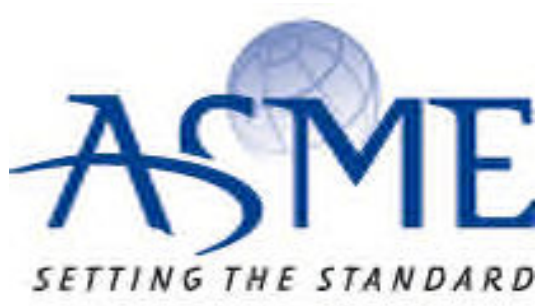

\title{
American Society of Mechanical Engineers
}

ASME Accepted Manuscript Repository

Institutional Repository Cover Sheet

Cranfield Collection of E-Research - CERES

ASME Paper Title: Modelling deformation of corroded buried steel pipes and design of protective measure

Authors: $\quad$ Alvan H. Wordu, Kong Fah Tee, Mahmood Shafiee

ASME Journal Title: Journal of Pressure Vessel Technology

Volume/Issue: Vol. 142, Iss. 1. 2020, Paper No: PVT-19-1077__ Date of Publication (VOR* Online) 18 October 2019

https://asmedigitalcollection.asme.org/pressurevesseltech/article/142/1/011801/1047015/Modeling-

ASME Digital Collection URL: Deformation-of-Corroded-Buried-Steel

DOI: $\quad$ https://doi.org/10.1115/1.4045025

*VOR (version of record) 


\title{
Modelling Deformation of Corroded Buried Steel Pipes and Design of Protective Measure
}

\author{
Alvan H. Wordu ${ }^{1}$, Kong Fah Tee ${ }^{1^{*}}$, Mahmood Shafiee ${ }^{2}$ \\ ${ }^{1}$ School of Engineering, University of Greenwich, Kent ME4 4TB, UK \\ ${ }^{2}$ Department of Energy and Power, Cranfield University, Bedfordshire MK43 OAL, UK
}

\begin{abstract}
Corrosion damage is reported to be one of the leading causes of steel pipeline failure causing significant financial losses to operators and damage to the surrounding environment. As part of a rising confrontation to pipeline integrity management, researchers are continuously seeking better ways to assist on how to identify, assess and prevent such incidents. Thus, there is a crucial need to establish a connection between assessment of pipeline condition and its structural stability. To achieve this, a 3-dimensional FE model is developed. The effects of geometry parameters such as defect thickness and spread angle are considered. Results show that thicker pipelines with corrosion groove perform better structurally than slender equivalents. The impact of corrosion damage is assessed to be significant on pipe stability with pipelines experiencing higher displacement and wall stresses with increasing defect depth and spread angle. A protective measure has been proposed using the buried pipes bedding system. The most critical spread angle is at 60 degrees for unprotected pipe sections and 90 degrees for bedded protected sections.
\end{abstract}

KEYWORDS: Corrosion; Buried Steel Pipelines; Deflection; Finite Element Modelling; Pipe Wall Thickness

*To whom correspondence should be addressed. Email: $\underline{\text { K.F.Tee@gre.ac.uk }}$

\section{INTRODUCTION}

Predicting structural failure in buried facilities is typically a complex task. This is as a result of the unseen conditions and nonlinearity interacting behaviour between buried structure and its soil environment, which in countless cases are highly random [1]. Among these concealed facilities, flexible pipelines are crucial. This is due to their enormous benefits, as they assist in 
providing a convenient and safe medium for transporting water, fossil fuels and other hydrocarbon compounds from the source of manufacture to where they are consumed [2-7].

However, due to the lengthy nature of pipelines, burying in the ground is a common practice and seems to be a more viable option as the surrounding soil provides protection to the pipeline from third party and other factors that could easily damage them. The backfilled earth also offers additional reinforcement to support the pipe walls from easily collapsing against overburden earth and passing traffic loads. Steel pipelines could easily fail when exposed to defects. The burying approach which conceal pipelines also make inspections difficult and expensive in the future to examine their structural wall conditions for possibility of deterioration. The number of aging buried pipelines in operation is expected to increase significantly every year, with growing number of corrosion damage related incidents [8-9]. The economic loss due to pipeline failure which arise from excessive deflection may be huge and hazardous. The safety assessment and accident prevention of buried pipelines is a difficult engineering problem, which relates to different factors like geotechnics and pipe material. Essentially, buried pipeline failure under vertical loading conditions results from large plastic deformation. When the stress level in the buried pipeline exceeds its limit of load bearing capacity, the pipeline will leak and fail. How to estimate the limit of deflection of buried corroded pipeline under vertical loading condition plays an important role in guiding the theoretical design and safety evaluation of buried pipelines [10].

Corrosion causes damage to metal components through a process of chemical or electrochemical reaction between the pipeline and its environment. The process initiates a reaction and cause the metal to be eaten away while producing oxides or other compounds over a small or large surface area. The reaction is continued and eventually causes the metal component to lose wall thickness over time, which can carry on until the metal is dissolved completely. The common types of corrosion found on steel pipes can be classified into these forms; uniform, galvanic, crevice, pitting, inter-granular, selective leaching, erosion corrosion and stress corrosion cracking (SCC) [11-12]. Buried steel pipeline in this category will typically become structurally weakened owing to an addition of imposed deformation that can be linked with the development of excessive deflection, high stresses and strains in critical locations, which might be well above the elastic range of the pipeline wall material leading to inevitable collapse failure [13]. 
Corrosion damage has been widely reported as the primary cause of ultimate strength reduction in steel pipelines [14-16]. These studies indicate that the maximum cross-sectional loss is a good parameter to correlate the residual load-bearing capacity of damaged pipeline. Other related studies on corroded tubes suggests that the presence of corrosion in the internal or external surface of a pipeline wall, may result in a serious threat to the structural integrity of the pipeline [17-22].

Past research has demonstrated the importance of numerical modelling evaluation for several structures, such as pipelines facilities, and assessed their mathematical models using FE modelling to study the behaviour of buried pipelines under surface loading and have received significant attention. Some of the first applications of numerical modelling was carried out in 1956 by Turner which is used for solving stress related engineering problems [23]. Ever since the method has become widely accepted in numerous engineering disciplines. Katona et al. [24] began the initial use of adopting FE method in solving problems related to buried pipelines with further studies carried out such as [25-28] further contributed to improving the developed method.

Lately published works have continued showing the reliability of using numerical modelling in predicting buried pipeline problems. For instance, El-taher and Moore [29] used FE to study stability of corroded metal culverts. Lui et al. [30] analysed failure of natural gas buried X65 steel pipeline against deflection load. Vettorelo et al. [31] used numerical modelling to study the influence of geosynthetic material buried depth on the deflection of buried pipelines. Yu et al. [32] assessed the effects of local random pitting on the collapse pressure of 2D ring under external pressure. Alzabeebee et al. [33] used numerical modelling to determine the minimum wall thickness on different pipe diameters by means of design performance parameters. Alzabeebee et al. [34] further compared the response of buried pipes under static and moving loads. However, these studies did not take into consideration the effect of defect on the buried pipelines. In summary, it cannot be established from these reviews, if internal corrosion damage will significantly reduce the performance of buried pipelines. Therefore, this study will aim at using deflection and wall stresses as a measure to assess the impact of corrosion location on damaged steel pipelines. 


\section{DESIGN FOR VERTICALLY LOADED FLEXIBLE PIPES}

\subsection{Failure Criteria}

In buried pipelines, the governing design parameter is often collapse failure. Factors which affect pipeline collapse are its diameter to wall thickness ratio, $O D / t(O D$ is outside diameter of pipe, $t$ is wall thickness), material properties such as Young's modulus and yield stress, wall thickness reduction caused by corrosion or wear, ovality and so on. Therefore, a good understanding on how these parameters impact on the behaviour such as collapse when corroded often will lead to safer designs and reliable operations. With this in mind, reliable prediction with the use of finite element (FE) modelling are beneficial in speedily estimating this kind of conditions.

While internal pressure is the prevailing load for surface pipelines, buried pipelines must be designed to withstand collapse due to overburden soil and live loads from application of repeated traffic or heavy static vehicles [35]. The failure of a pipeline can be characterized by excessive deflection, actual buckling pressure greater than critical buckling pressure, and excessive tensile stress resulting from over pressurization. All of these modes are important but deflection and buckling stresses are considered as the main criteria for assessment as it is the main performance parameter generally adopted in design of flexible buried pipelines under vertical loading conditions [36-39]. A number of studies such as [40-42] provided results of FE analysis and closed form solutions for these two failure modes.

Nevertheless, there may be circumstances where buckling may be used to check the design of buried flexible pipelines. These are for pipelines at shallow depths of cover with internal pressure as well as for submerged pipelines at shallow depth of cover with atmospheric internal pressure [37]. Since the case being considered does not match the conditions for including buckling assessment, this study will only be measuring for excessive deflection. Thus excessive deflection is used as the criteria for determining the pipeline failure [36-38]. For a flexible pipe system, a failure from external loading can be defined by the point at which the top of the pipe starts experiencing inverse curvature [43].

\subsection{Deflection Analysis}

There are two main types of pipes, rigid and flexible. A flexible pipe can easily deflect without structural distress to its pipe wall. Types of flexible pipes are steel, ductile iron (DI), polyvinyl chloride (PVC), high density polyethylene (HDPE) and fiberglass. One of the design 
considerations for flexible pipe is the deflection of the pipe due to dead and live loads on the pipe. The conventional design procedure demands that the geometric details of the buried pipeline should certify some performance limit; where the predicted deflection should be within tolerable limits. For steel pipes, the critical or allowable deflection $\left(\Delta y_{c r}\right)$ is taken as $2 \%$ of pipe diameter [44-46].

The deflection of flexible pipe can be measured in terms of the vertical decrease, $\Delta Y$ (or horizontal increase, $\Delta X$ ) to the original pipe diameter, $O D$. Flexible pipes will ideally deflect in an elliptical configuration. This deflection is needed to mobilize the lateral soil support, and to combine with the inherent pipe strength to support the load on the pipe. The load hypothesis assumes the parabolic distribution of passive horizontal pressure on the sides of the buried pipe as shown in Fig. 1. The load on a buried pipe is created by backfill soil placed over the top of the pipe and any surcharge or live load on the backfill surface over the pipe. Flexible pipe is designed to transmit the load on the pipe to the soil at the sides of the pipe. As the load on the pipe increases, the vertical diameter of the pipe decreases, and the horizontal diameter increases. The increase in horizontal diameter is resisted by the stiffness of the soil at the sides of the pipe.

In design of structural members, the strain or deformation of an element of the material being used can be determined from the ratio of the load or the stress on the member to its modulus of elasticity (strain $=$ stress/modulus of elasticity). Currently, there are various methods for estimating pipe deflection and various parameters for each method. Some of the fundamental analytical solutions used in practice to measure the deflection of buried flexible pipeline are presented below. These closed form solutions were developed many years back and adopted across the pipeline industry. 


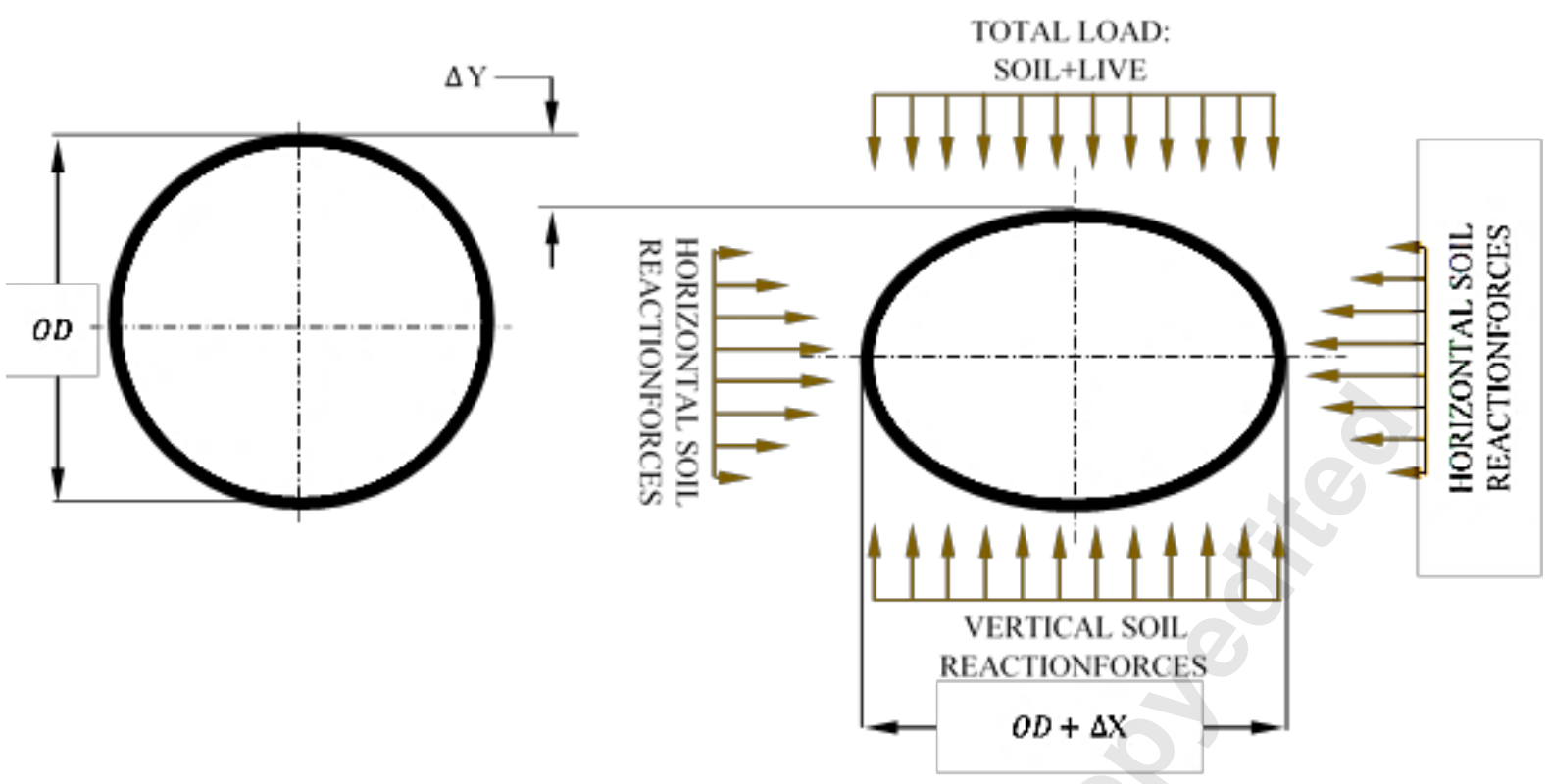

Figure 1. Theoretical Load Distribution in Buried Flexible Pipe Deflection.

\subsubsection{Iowa equation}

Spangler [47] developed the following semi-empirical equation based on the modified Iowa formula for calculating the deflection $\Delta X$, of buried flexible pipe-soil systems under earth load.

$$
\Delta X=\frac{D_{L} K_{B} W_{c}}{\left(E I / R^{3}\right)+0.061 E^{*}}
$$

where $D_{L}=$ deflection lag factor; $K_{B}=$ bedding constant; and $W_{c}=$ Marston's load i.e. the vertical load per unit length. The expression $E_{p} I / R^{3}$ represents the pipes stiffness, where the following terms $E$, $I$ and $R$ represent modulus of elasticity, moment of inertia of wall cross section per unit length of pipe and mean radius of pipe, respectively. The soil stiffness is represented in terms of $0.061 E^{*}$, where $E^{*}$ is the modulus of soil reaction.

\subsubsection{McGrath's equation}

This solution takes into account the effect of hoop compression and effect of bending moment in its deflection equation. Here, deflection $\Delta_{y}$ is expressed in percentage as:

$$
\frac{\Delta_{y}}{D}(\%)=\left[\frac{q}{\left(\frac{E_{P} \cdot A_{P}}{R}+0.57 M_{S}\right)}+\frac{K_{B} \cdot q \cdot D_{L}}{\left(\frac{E_{P} \cdot I}{R^{3}}+0.061 M_{S}\right)}\right] X 100
$$


where $q=$ vertical stress on pipes crown; $K_{B}=$ bedding factor; $D_{L}=$ deflection lag factor; $E_{P}=$ modulus of elasticity of pipe; $A_{P}=$ area of pipe per unit length; $R=$ pipe radius and $M_{S}=$ modulus of soil reaction.

\subsubsection{BS EN 1295:1 equation}

According to BS EN 1295:1 [48], the actual deflection in terms of vertical decrease of buried flexible pipe $\Delta_{y}$ can be evaluated using the Eq. (3):

$$
\Delta_{y}=\frac{K_{B}\left(D_{L} w_{c}+P_{s}\right)}{\left(\frac{8 E_{p} I}{D^{3}}+0.061 E^{*}\right)}
$$

where

$$
\begin{gathered}
P_{S}=\frac{W_{S} I_{F}}{L_{1} L_{2}} \\
W_{c}=\gamma_{S} H \\
D=D_{i}+2 c \\
E^{*}=\frac{k^{*} E_{S}\left(1-v_{S}\right)}{\left(1+v_{S}\right)\left(1-2 v_{S}\right)} \\
I_{F}=1.0 \text { for }(H \geq 0.9 m \\
L_{1}=0.253+1.75 H \\
L_{2}=0.51+1.75 H: \text { For }(0.6 \mathrm{~m}<\mathrm{H}<0.76 \mathrm{~m}) \\
L_{2}=13.31+1.75 H / 1.8: \text { For }(\mathrm{H}>0.76 \mathrm{~m})
\end{gathered}
$$

From the above solution, $K_{B}=$ deflection coefficient; the loads exerted on the pipe system are governed by the expression $D_{L} W_{C}+P_{S}$, where $D_{L}=$ deflection lag factor; $W_{c}=$ soil load, and $P_{s}=$ live load. Further expressions include: $E_{p}=$ modulus of elasticity of pipe material; $I=$ moment of inertia; $D=$ mean diameter; $E^{*}=$ modulus of soil reaction; $W_{S}=$ traffic load; $I_{F}$ =impact factor; $L_{1}$ and $L_{2}=$ load width parallel and perpendicular to travel direction; $\gamma_{S}=$ unit weight of soil; $H=$ height of soil; $D_{i}=$ inside diameter; $c=$ distance from inside diameter to neutral axis; $E_{s}=$ modulus of soil; and $K^{*}=$ numerical value which depends on poison's ratio of soil, $v_{s}$. 


\section{METHODOLOGY}

\subsection{Numerical Model}

The structural behaviour of vertically loaded buried pipe can be modelled by two popular methods: three-dimensional solid mechanics; or the specialised beam element for pipe and Winker springs for soil boundary. The use of Winkler type soil models is shown to have significant limitations. This is because, the reaction of the springs are restricted in a way that displacement is in one direction and unable to account for the effect of loading direction. Despite studies have shown the special beam approach involves less computational power, the three dimensional solid mechanics method was adopted in this study as it represents a more realistic behaviour of the physical interaction between soil and buried structure [49-50]. The model was developed in the framework of COMSOL Multiphysics software to simulate behaviour and deformation of soil in a way to allow the pipe performance criteria get evaluated with good level of accuracy. This was achieved by integrating the pipe domain along with the surrounding soil domains using appropriate boundary conditions and very well refined meshing distributions. The model was developed in two pipeline categories, one without defect (intact or healthy pipe) and the second with corrosion. The healthy pipe model was set up to serve as a calibrator for the damaged buried pipeline model.

\subsection{Model Setup}

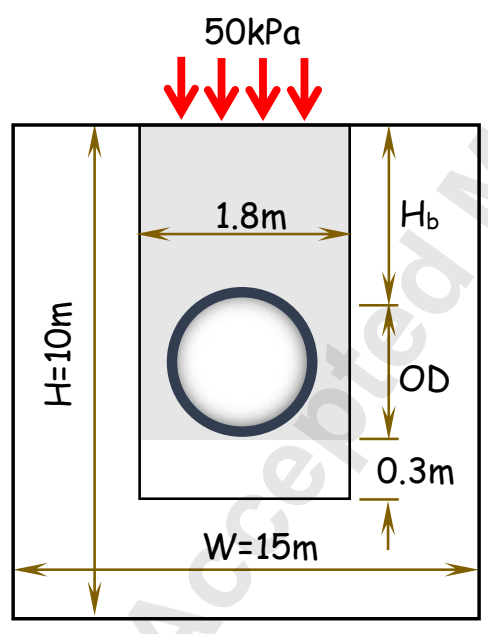

(a) Front

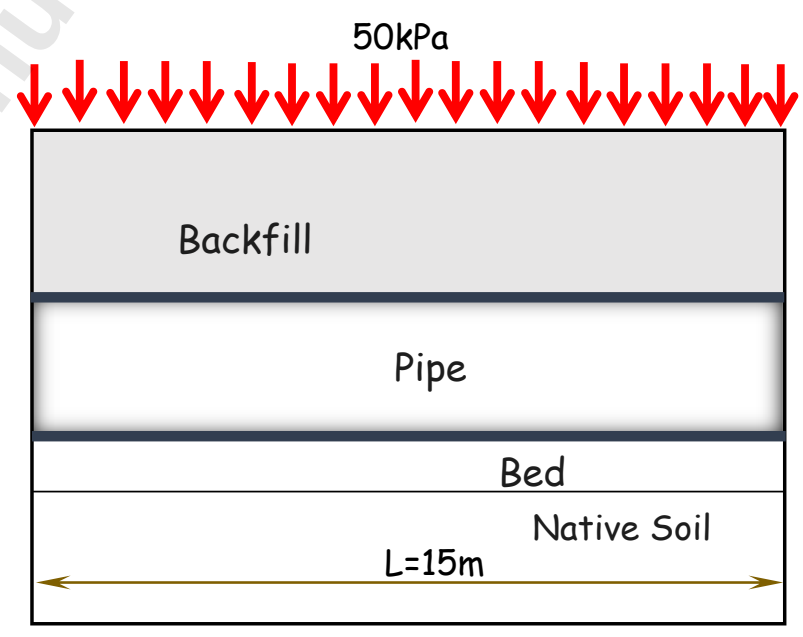

(b) Side

Figure 2. Schematic diagram for model profile 

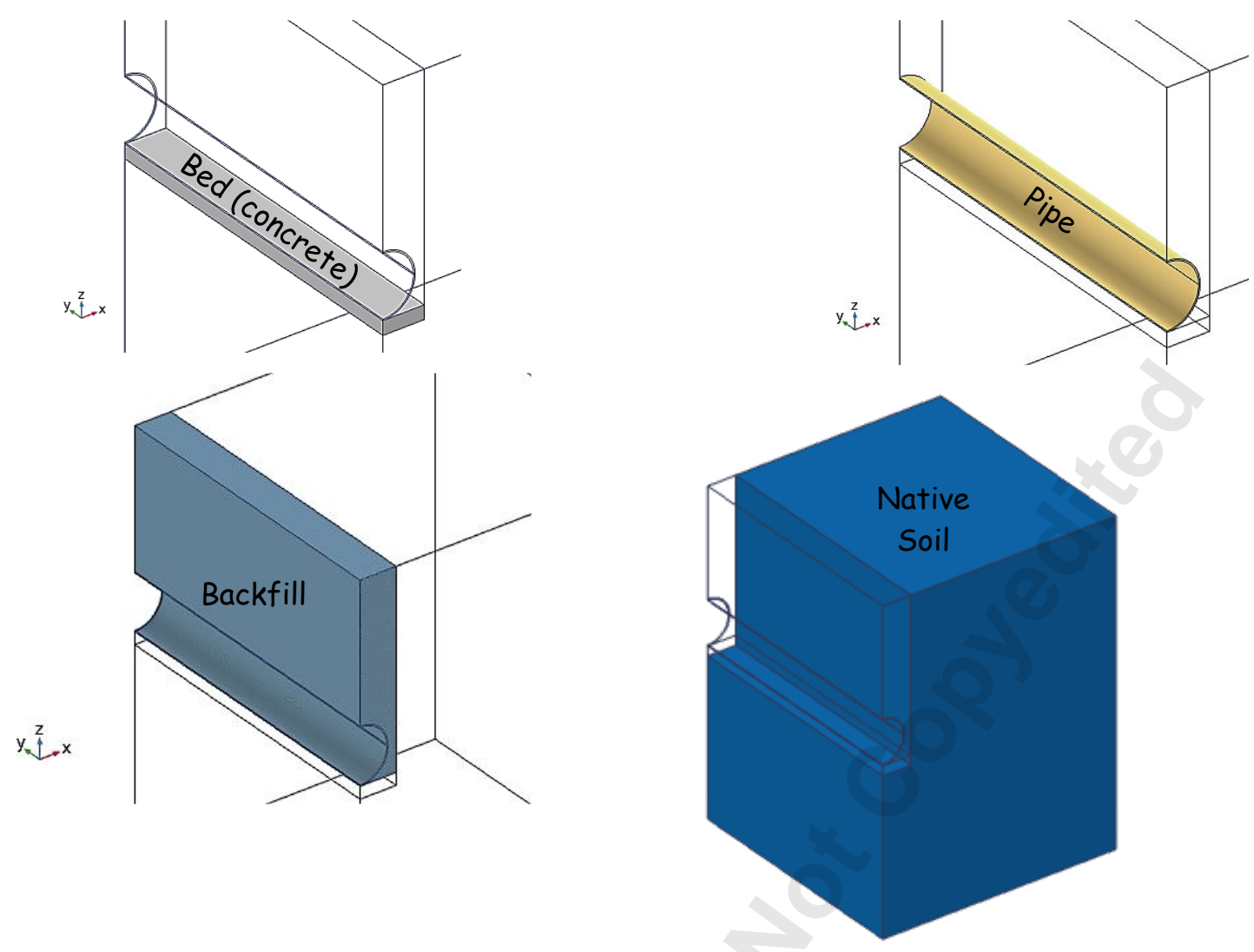

Figure 3. FE model with coupled domains

To model buried pipelines, there is a need to adopt a suitable geometry and appropriate material properties. The model was established after carrying out careful review of past studies relating to the numerical modelling on vertically loaded buried pipelines [36-38]. These studies adopted a narrow trench condition where the pipeline is installed in an excavated trench that is comparatively narrow, such that the vertical load on the pipeline wall is reduced by the adjacent soil prisms. Figure 2 shows the idealised representation for the developed model with profile length $(L)$, width $(W)$ and depth $(H)$ of $15 \mathrm{~m}, 15 \mathrm{~m}$ and $10 \mathrm{~m}$. A uniformly distributed vehicular load of $50 \mathrm{kPa}$ is assumed to be acting on the top of the backfill soil domain with a buried pipeline of wall thickness and outside diameter of $6 \mathrm{~mm}$ and $1400 \mathrm{~mm}$, respectively. The pipeline is position within the backfill soil at a depth $(H b)$ of $3.4 \mathrm{~m}$ and is supported on a concrete bed foundation of $0.3 \mathrm{~m}$ thickness which is typically used for such buried conditions. Figure 3 shows four of the coupled domains in the model considered for a typical buried pipeline condition. These are consisting of a pipeline domain and three geo-mechanical material blocks; backfill, bed and native soil. The entire profile is coupled and analysed as reduced quarter linear elastic problem, to allow for reduced savings in computational time. Mechanical properties from Table 1 [37] are assigned to the respective domains. 
Table 1. Mechanical Properties of Soil and Pipe

\begin{tabular}{lcccc}
\hline Material properties & Pipe & Native soil & Backfill & Bed \\
\hline Unit weight $(\gamma)$ & $78.5 \mathrm{kN} / \mathrm{m}^{3}$ & $20 \mathrm{kN} / \mathrm{m}^{3}$ & $16 \mathrm{kN} / \mathrm{m}^{3}$ & $23 \mathrm{kN} / \mathrm{m}^{3}$ \\
Elastic modulus & $2.15 \times 10^{11} \mathrm{~Pa}$ & $6.77 \times 10^{6} \mathrm{~Pa}$ & $2.39 \times 10^{6} \mathrm{~Pa}$ & $25 \times 10^{9} \mathrm{~Pa}$ \\
Poison's ratio $(v)$ & 0.30 & 0.34 & 0.21 & 0.20 \\
\hline
\end{tabular}

\subsection{Modelling of Pipeline Corrosion}

Pipeline corrosion is modelled by material removal from the inner surrounding face of the pipeline wall. This is then coupled with the geometric domains consisting backfill, concrete bed and native soil. Figure 4 shows uniformly corroded pipeline section with internal damaged groove at pipes invert. The thickness of damaged pipe wall section $\left(t-t_{1}\right)$ is subtracted from that of the total wall thickness $(t)$. The geometry of the pipe containing defect and position is further described by other parameters such as pipe length $(L)$, defect depth $\left(t_{1}\right)$ and spread angle $(Q)$. This configuration is considered among the best conventional method to adopt when representing steel pipeline with uniform corrosion damage.

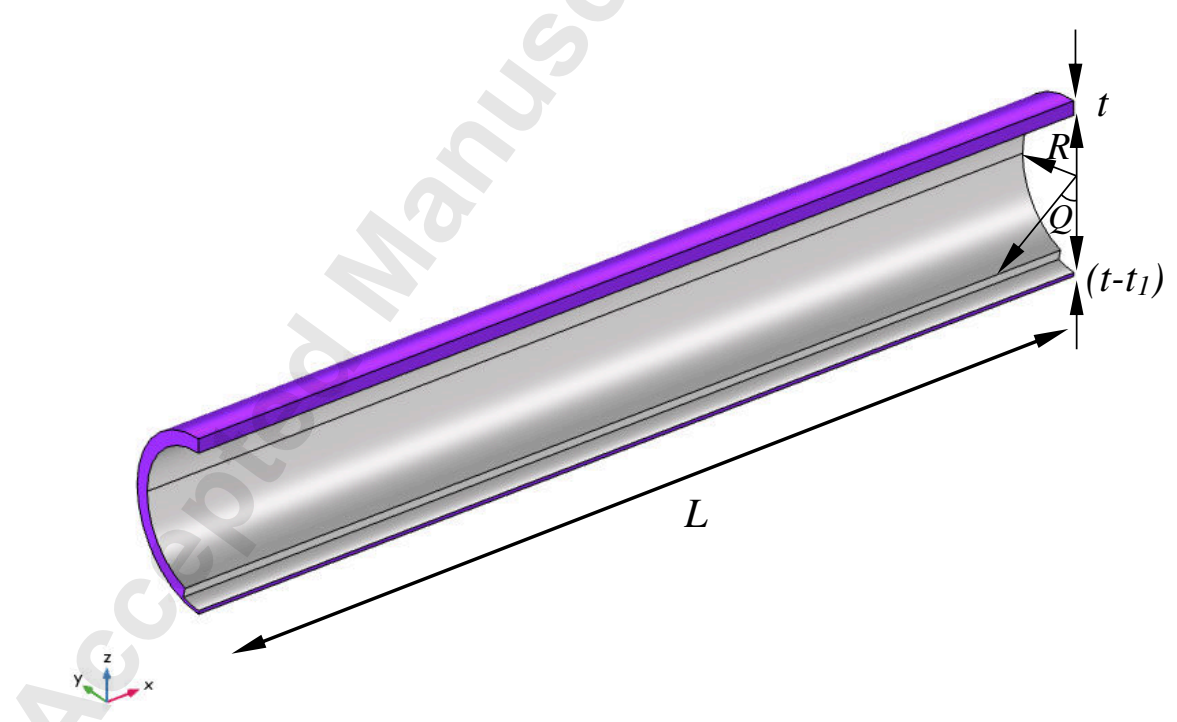

Figure 4. Pipeline and defect geometric parameters. 


\subsection{Boundary Condition and Meshing}
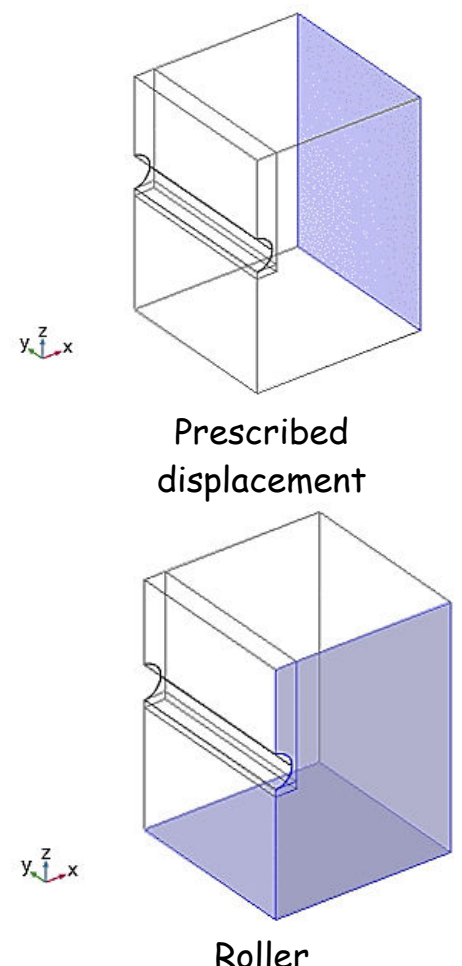

Roller

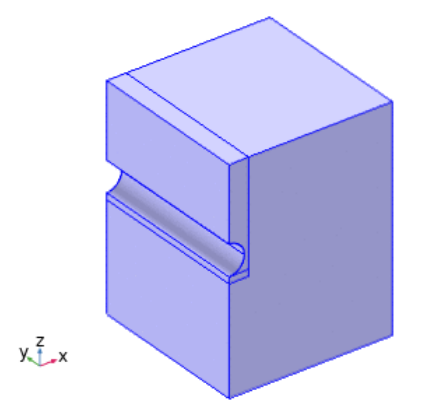

Gravity

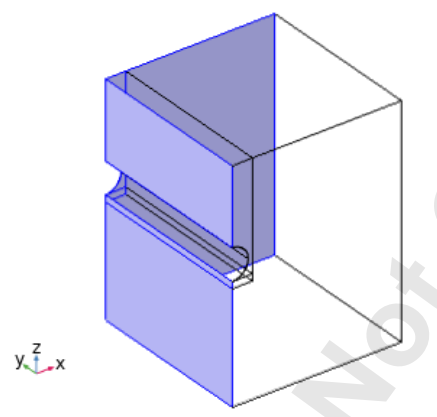

Symmetry

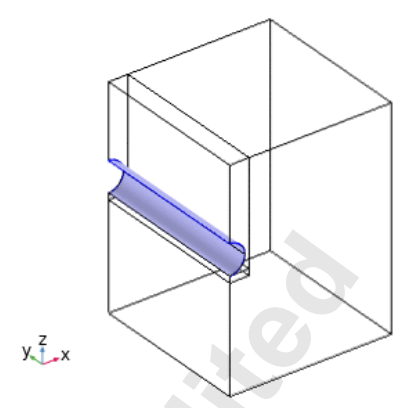

Contact

(between pipe and soil)

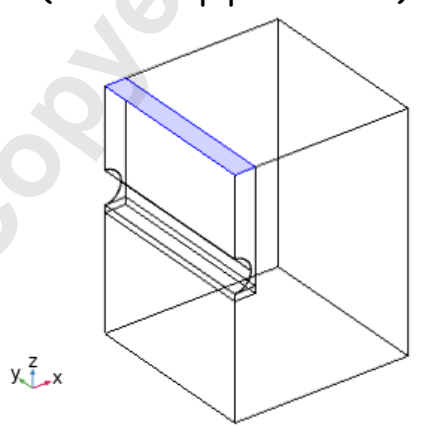

Surface load

Figure 5. Boundary conditions adopted

Several boundary types have been applied on various buried pipeline models, which include roller, fixed and symmetry boundary conditions. The application of a boundary type to a domain in a given situation determines the behaviour of soil-pipe system during analysis and what result that would be achieved. In this study, the boundary conditions are adopted after reviewing buried pipeline problems and sensitivity analysis. Fig. 5 shows the boundary conditions adopted and the surfaces assigned. The vehicular load is applied with load boundary to the top of the backfill soil, while the effect of gravity is applied to the entire model with value of minus $9.8 \mathrm{~m} / \mathrm{s}^{2}$. Furthermore, a prescribed displacement of zero is assigned in $\mathrm{X}, \mathrm{Y}$, and $\mathrm{Z}$ directions to the native soil back surface to allow for pipeline to deflect in the horizontal direction under the combined soil and vehicular load. However, it is crucial to note that the interaction between the pipe and its surrounding domains of backfill, bed and native soil are made possible with the addition of contact pair interface. Without this interface, the pipe and backfill domains will be locked together and there will be no relative displacement between 
the two. The interaction between the pipe and backfill consists of elastic perfectly plastic solid boundaries. In addition, friction behaviour between the pipe and backfill is added through the contact pair using friction attribute element. A static friction coefficient of 0.45 is used to simulate the roughness between pipe and soil, typical of this composition.

Figure 6 shows meshed model with meshing configuration of three meshing sequences adopted to improve mesh refinement while reducing number meshed elements, to improve result accuracy and to lower computational time. These are mapped, free triangular and swept mesh functions. After the completed mesh, a total of $556.9 \mathrm{~m}^{3}$ mesh volume is generated with 1536 number of elements meshed (comprising of 1472 prisms, 64 hexahedra, 1472 triangles, 486 quads, 456 edge element and 34 vertex elements), as well as a minimum element quality of 0.01 and average element quality of 0.8 is achieved.

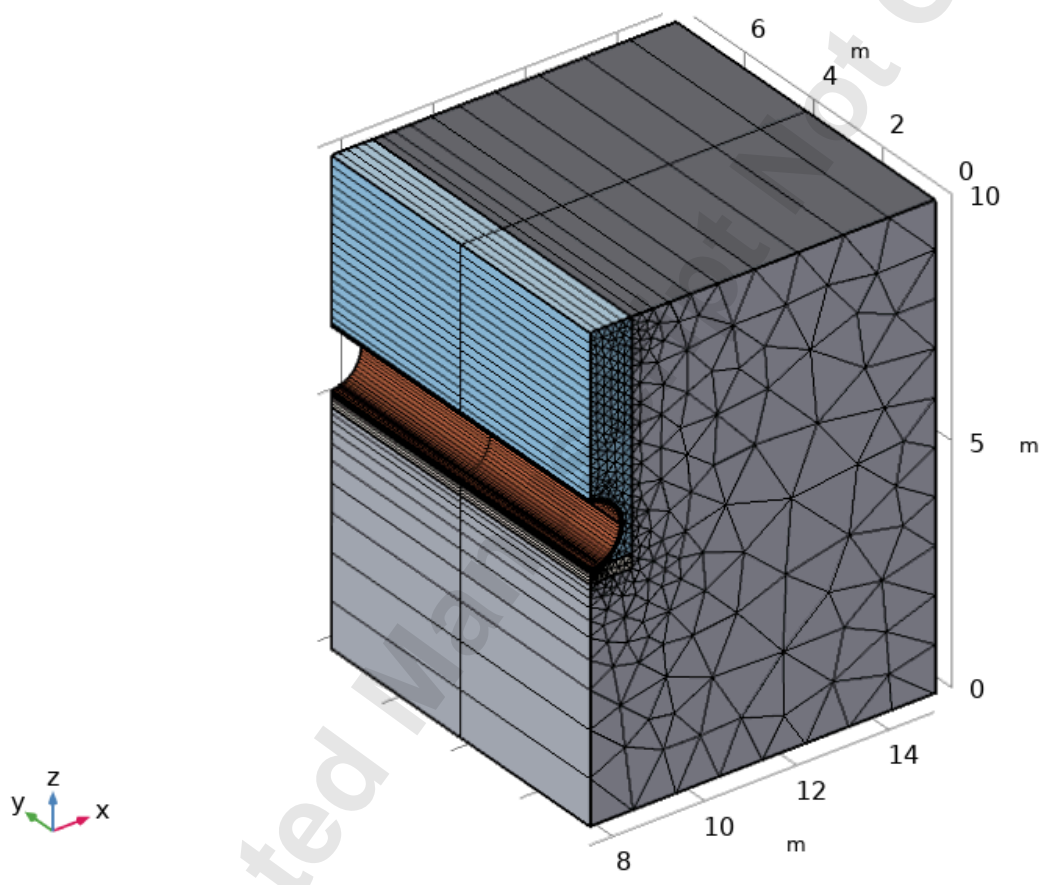

Figure 6. FE model with mesh distribution.

\section{RESULTS AND DISCUSSIONS}

\subsection{Comparison of FEM results and analytical measurements}

The buried pipeline response in terms of measured deflection is predicted using proposed FE model. The model results are validated against design standards and are presented in Fig. 7. 
These results are for intact pipeline condition with various values of wall thicknesses of 6, 9.53, $12.7,17.48,23.83,26.97,31.75 \mathrm{~mm}$ and in all the cases the outer pipeline diameter is considered as $1.4 \mathrm{~m}$. The results in Fig. 7 show that pipes with slender wall thickness deflect more than their thicker counterparts as a result in reduction of pipe stiffness. The deflection results from the proposed model show good agreement and behaviour with the corresponding design standards. However, there are some little deviation as the proposed FE model solution is between the BS EN1295:1 and Iowa solutions. This could be as a result of how deflection is measured in terms of direction. For instance, BS EN 1295:1 design code measures deflection in vertical decrease while the Iowa and McGrath equations predict deflection in terms of pipeline horizontal increase. Other factors that could be responsible for this little deviation might be that the analytical solutions only consider the stiffness provided by one geomechanical material but in the case of the proposed model all the three materials are considered. According to [51], the Iowa and McGrath solutions have some drawbacks, and their application is limited to cases in which the pipeline is installed in a relatively uniform soil and does not include stiffness of the native soil adjacent to the pipeline trench, in this case which is backfill. Furthermore, due to the over conservative factor of safety factor of BS EN 1295:1, the predicted deflection values are a little greater than those estimated using the proposed model.

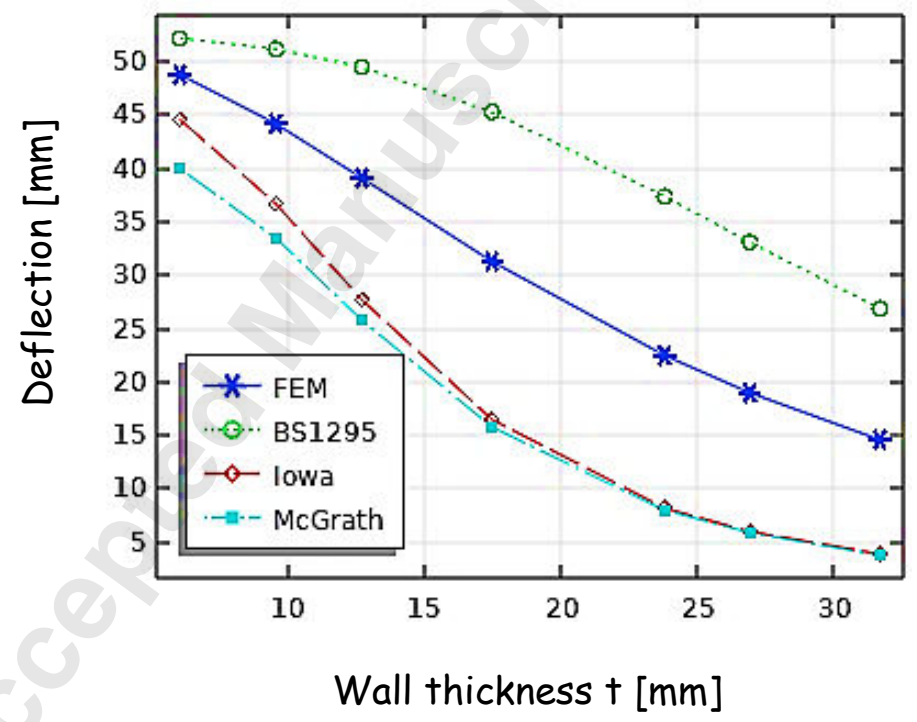

Figure 7. Deflection results of intact buried pipe for proposed model (FEM) and available design standards 


\subsection{Effect of defeat parameters}

Parametric studies were conducted using proposed FE model with two defect parameters; spread angle $Q$, and defect thickness, $t_{1}$ (see Fig 4) to study the pipes behaviour. Both parameters were selected because they form the crucial defect configuration that is responsible for loss in mass or thickness of the steel pipe due to corrosion. The buried pipe responses were measured in terms of excessive deflection and elevated stress levels. The model profile remains the same, with pipe outside diameter, $O D=1.4 \mathrm{~m}$ and pipes wall thickness, $t$ varies from $6 \mathrm{~mm}$ to $31.75 \mathrm{~mm}$. The corrosion spread angle, $Q=15^{\circ}$ to $120^{\circ}$; and defect thicknesses $t_{1}=0.8 t$ which is based on evaluation of the worst state of the pipe deterioration.

Figs. 8 and 9 show the deflection and von Mises stress results from the parametric studies for the effect of defect spread angle, $Q$ for $15^{\circ}, 30^{\circ}, 60^{\circ}, 90^{\circ}$ and $120^{\circ}$. Since the criterion for failure in this study is based on the critical deflection steel pipes, which is $2 \%$ of the pipes outside diameter, the assumption here is that at displacement above $28 \mathrm{~mm}$, the pipe is assumed to have gone above safe limit and would be deemed unsatisfactory and prone to failure. Based on this assumption of failure, it can be seen in Fig. 8, an increase in the defect spread angle results in an increase in deflection. The pipe structure will deflect excessively when $Q$ grows above $60^{\circ}$ and when the wall thickness is less than $18 \mathrm{~mm}$ due to weakened pipe stiffness. However, from Fig. 9 the pipe reaches a high level of stress above $400 \mathrm{MPa}$ at $Q=60^{\circ}$ and $90^{\circ}$.

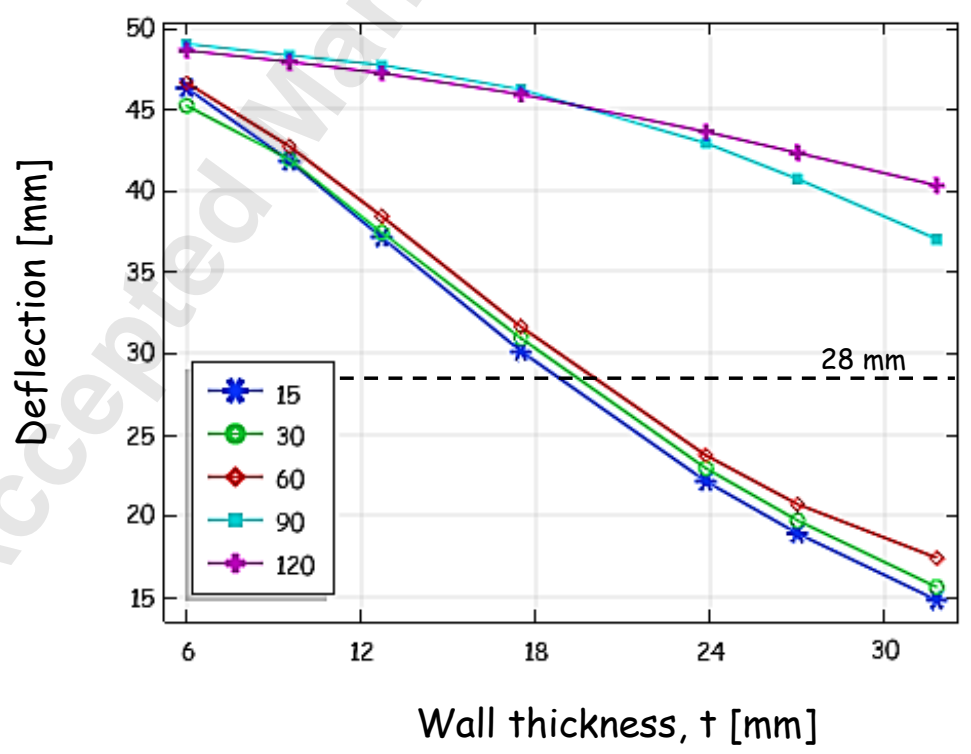

Figure 8. Deflection for buried pipeline with defect damage at pipes invert for different spread angles 


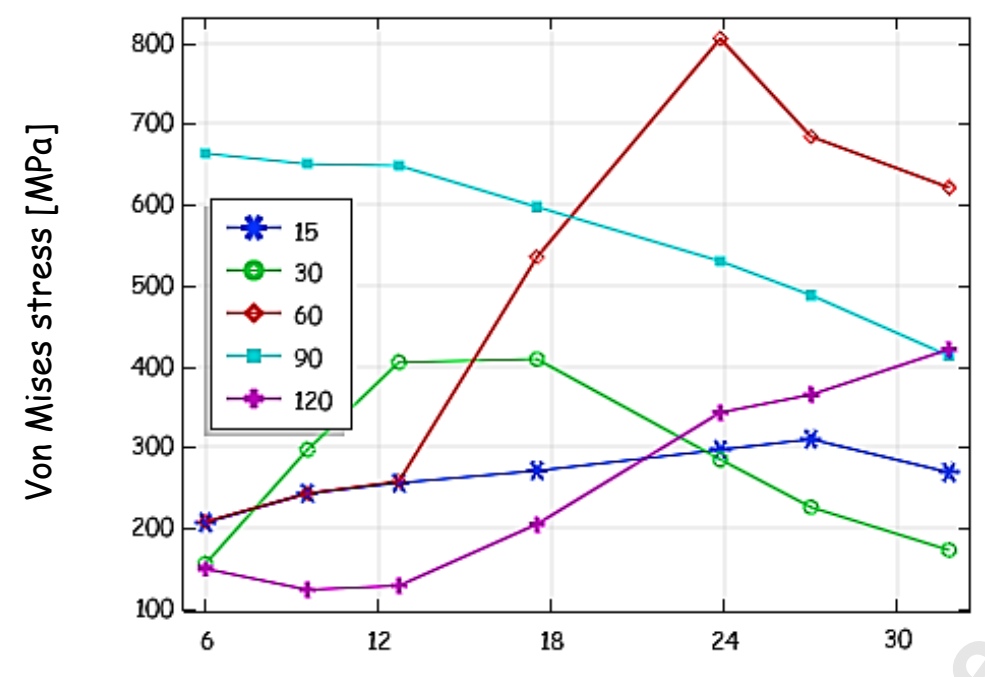

Wall thickness, $+[\mathrm{mm}]$

Figure 9. von Mises stress for buried pipeline damaged at invert for different spread angles

\section{DESIGN OF PROTECTIVE MEASURE}

The collapse failure of vertically loaded buried pipelines could be prevented if protective measures are put in place. This section presents the protective measures that could be designed to safeguard pipelines from unwanted excessive deflection. Protective measures are designed to improve service conditions. For buried pipelines, these measures can be grouped into active defence method or passive ones [49]. The active process involves procedure like reducing the external load on the pipeline such as lowering the volume of traffic passing through or restricting certain categories of vehicle loads whereas the passive system encompasses the use of pipeline monitoring equipment, timely maintenance and overhauling of damaged pipe sections. Below are two methods of providing protective measure for intact and corroded buried flexible pipeline sections.

\subsection{Internal pressure}

Increasing or introducing internal pressure in an un-corroded pipeline has shown to reduce excessive deflection. This is because the internal pressure acts as an invisible strengthening mechanism to the pipe wall stiffness. The radial deformation of a buried intact pipeline caused by internal pressure could resist the deflection produced by external loads. As can be seen in Fig. 10, there is a clear relationship that increasing the pressure inside the pipe wall lowers the 
deflection. Most importantly the effect is more on pipes with $O D / t$ less than 80 (i.e. for pipes with $t$ between 17.48 to $6 \mathrm{~mm}$ ). Therefore with the current pipe size of $O D=1.4 \mathrm{~m}$, it is logical to adopt an internal pressure of $3 \mathrm{MPa}$ across the entire range of wall thickness as this produces deflections lower than the allowable limit of $28 \mathrm{~mm}$.

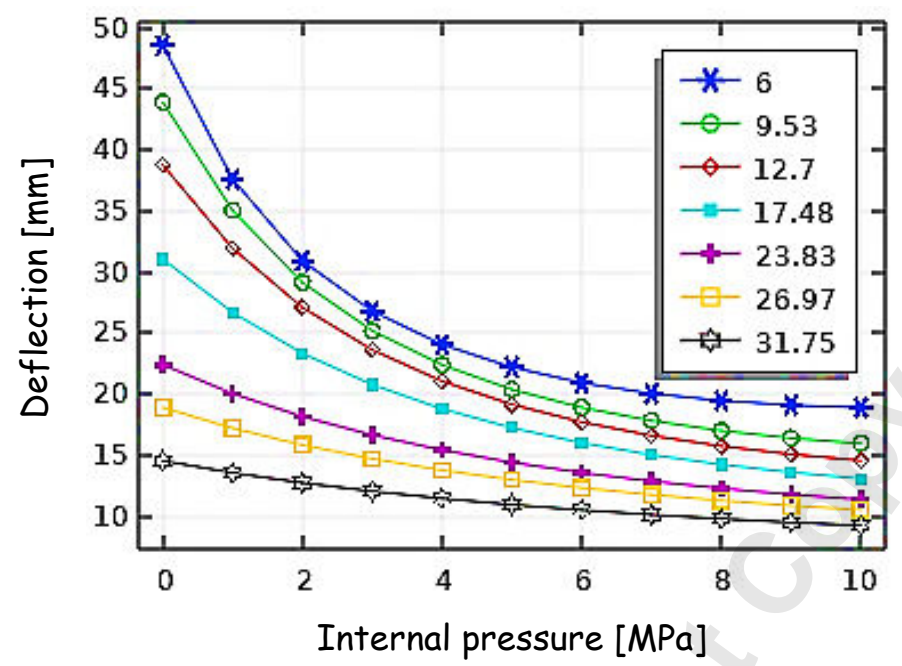

Figure 10. Deflection of intact pipeline under internal pressure

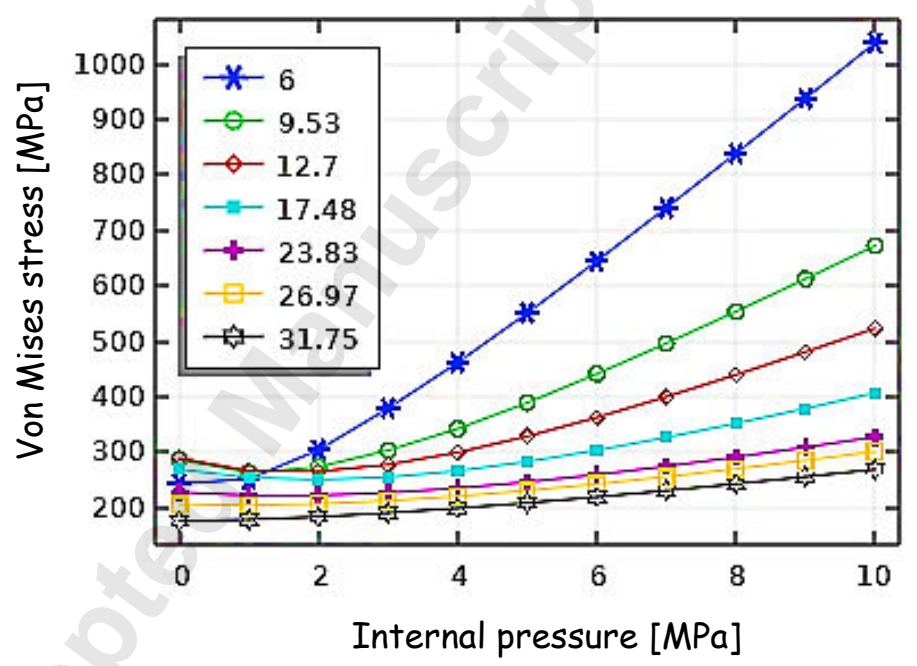

Figure 11. Von Mises stress of intact pipeline

However, caution should be taking into consideration as to what amount of pressure applied is safe without causing structural damage to the buried pipeline system, as it turns out that at certain high levels of internal pressure could lead to generation of high stresses that may exceed the yield strength of the pipeline material. Fig. 11 shows the estimated von Mises stresses across the various pipe wall thicknesses. It can be seen that increasing the internal pressure will 
certainly increase the strain on the pipe walls. If a typical case of a steel pipeline is considered with mechanical properties of yield and ultimate strength corresponding to 411 and $443 \mathrm{MPa}$ [52] respectively, the safe pressure to operate will be below $4 \mathrm{MPa}$. Similarly, pipelines with wall thickness greater than $23.83 \mathrm{~mm}$ does not have any significant rise in wall stresses at high levels in internal pressure.

\subsection{Bedding design}

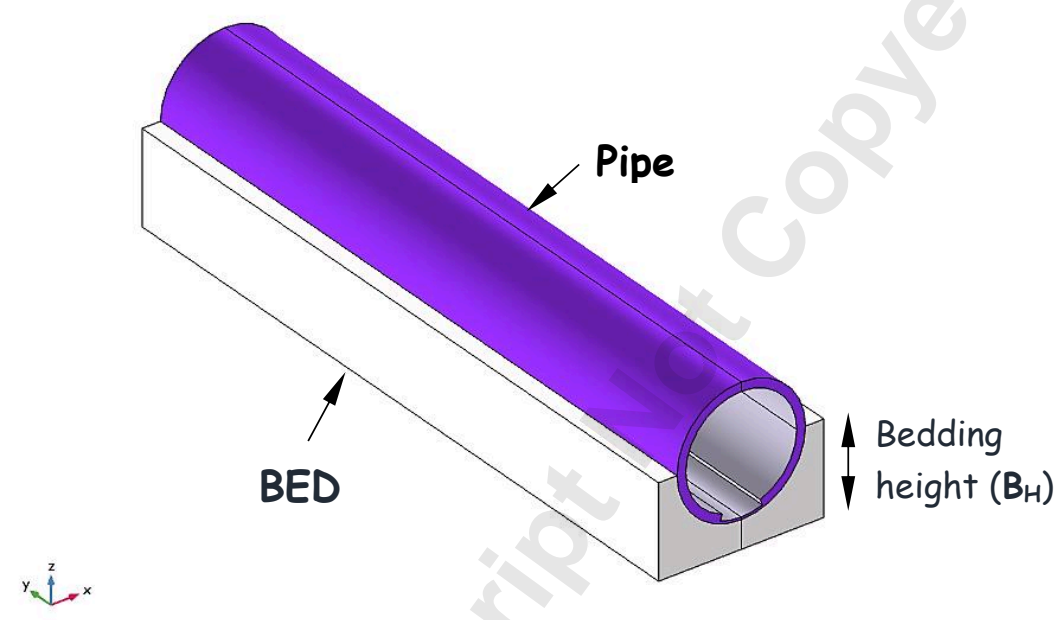

Figure 12. Description of protective bed for internally corroded pipeline

The addition of protective measure to buried pipeline design come at an additional cost to the pipeline operator. Therefore to lower cost while maintaining the desired improvement needed to keep the pipe system safe even after being exposed to such high level of corrosion damage, the authors have proposed the use of bedding as a protective measure as shown in Fig. 12. In this condition, the internal pressure mechanism will not be suitable, because there will be very high levels of stress concentrations at the damaged locations which may lead to burst failure. Also the decision is made because the bedding system requires the least attention after installation and the material volume (length $x$ depth $x$ width) required to support for the pipeline stability is lesser when compared to backfill and native soil, thereby offering huge savings to the pipeline operator. 


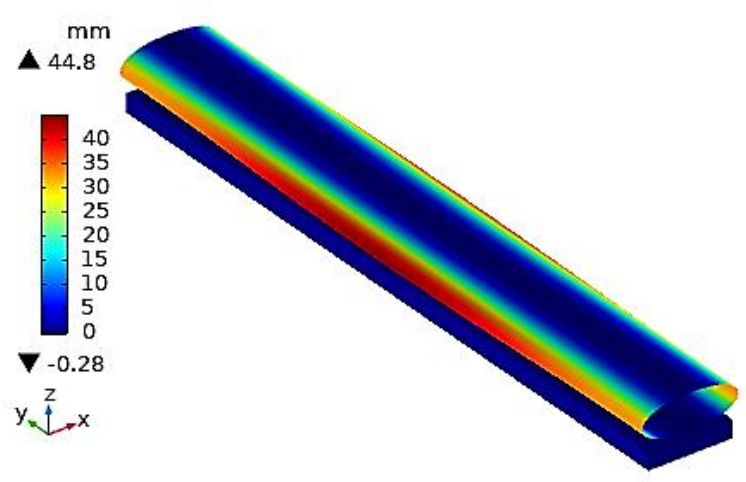

$B_{H}=0.0875 \mathrm{~m}$

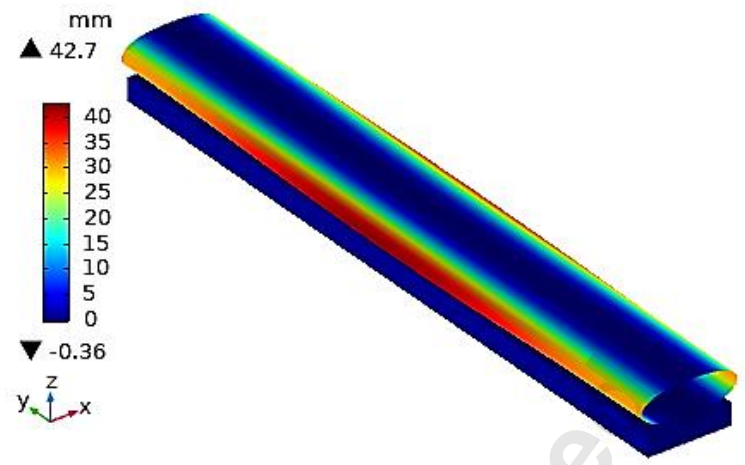

$B_{H}=0.175 m$

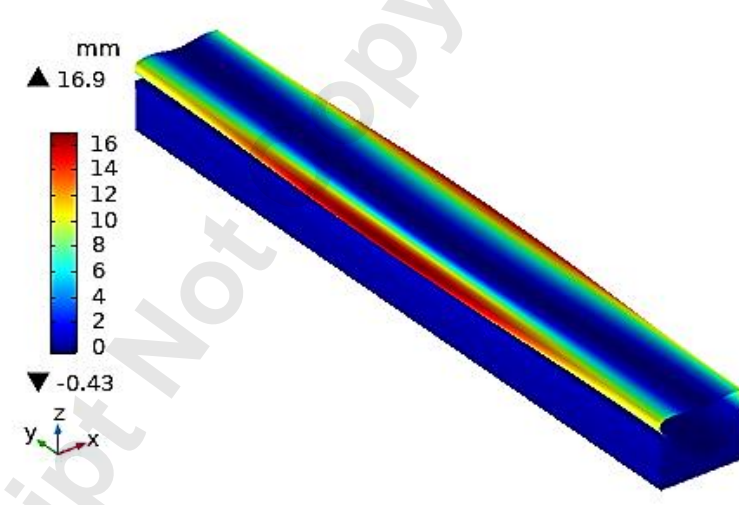

$B_{H}=0.35 \mathrm{~m}$

$$
\text { (7) } \mathrm{B}_{\mathrm{H}}=0.7 \mathrm{~m}
$$

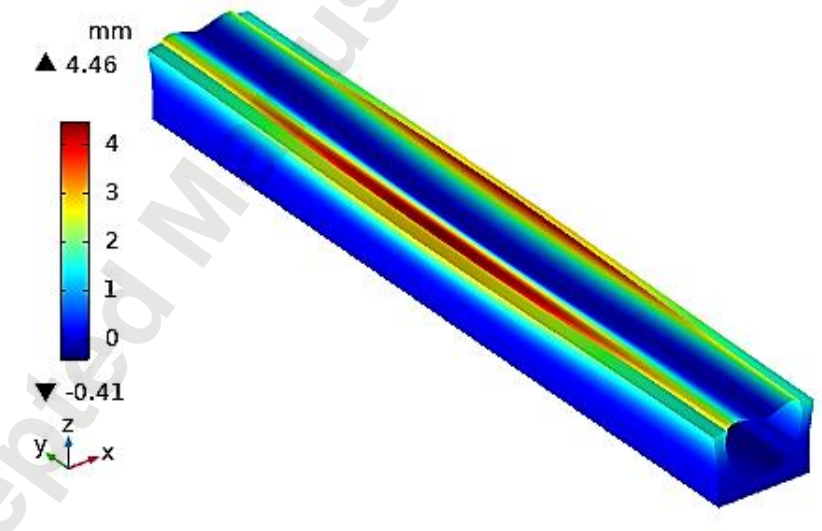

$B_{H}=1.05 m$

Figure 13. Deflections of corroded pipeline $\left(t=6 \mathrm{~mm} ; t 1=0.8 t ; Q=60^{\circ}\right)$ at different bedding depths. 


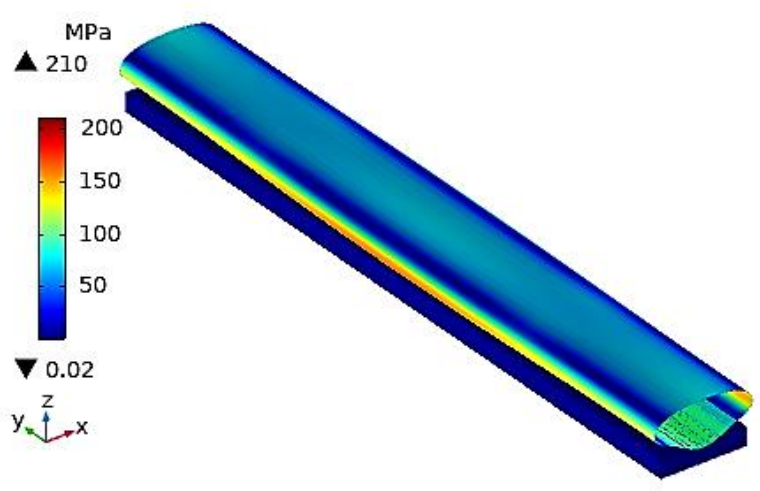

$B_{H}=0.0875 m$

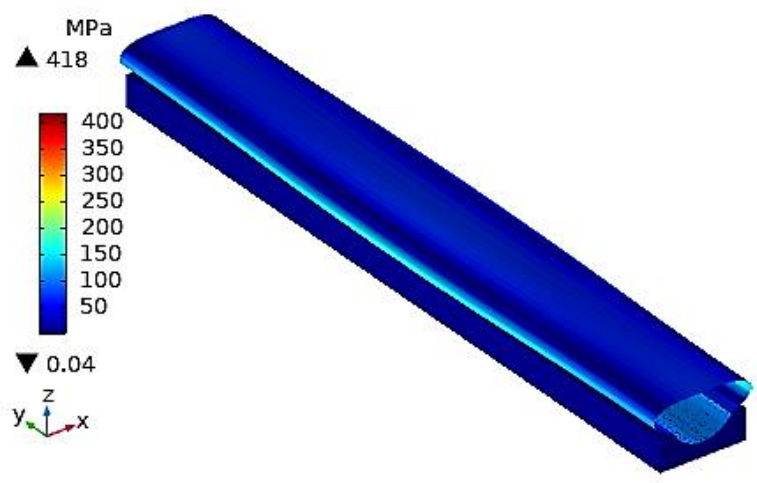

$B_{H}=0.35 \mathrm{~m}$

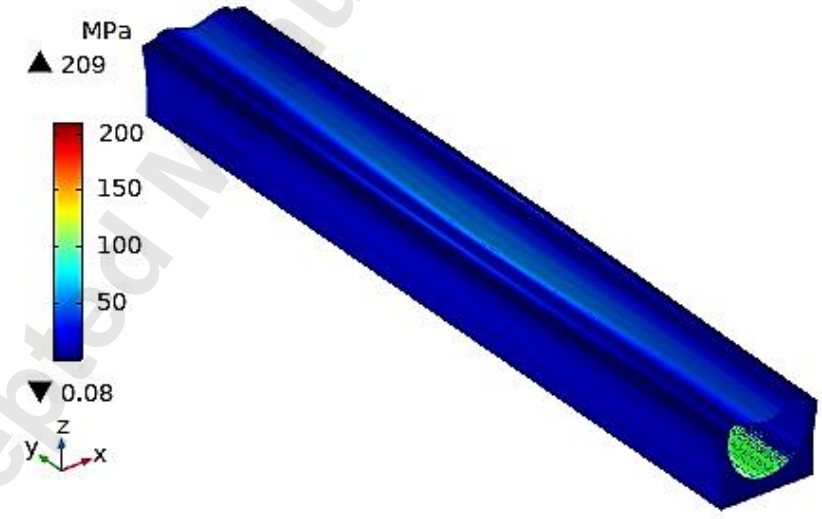

$B_{H}=1.05 m$

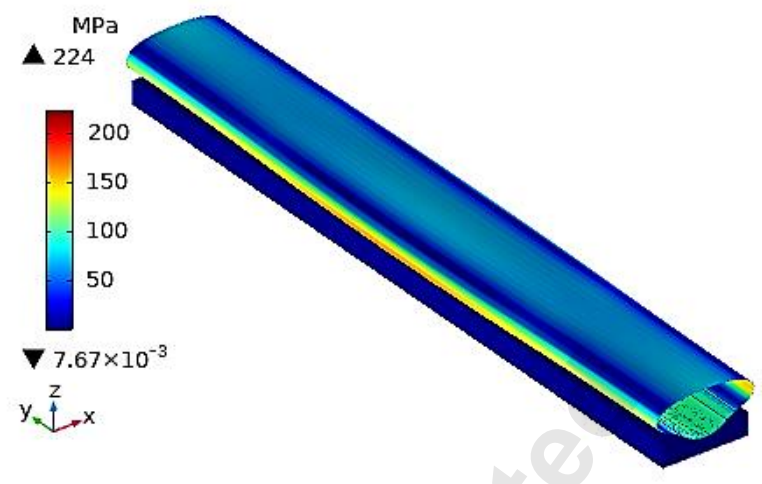

$B_{H}=0.175 m$

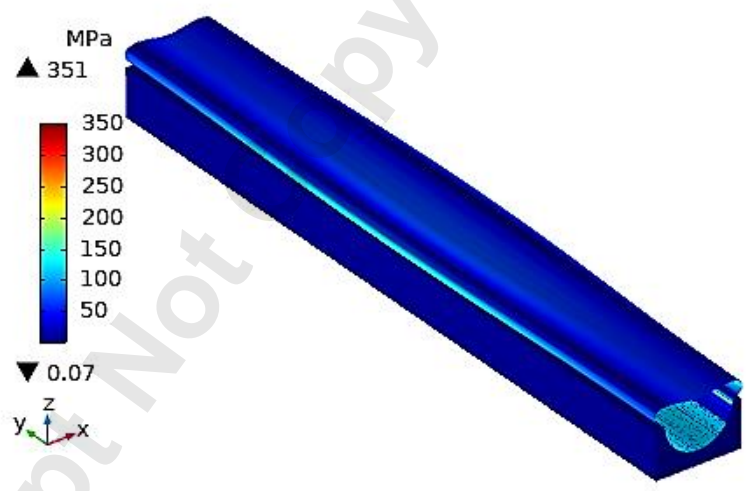

$B_{H}=0.7 m$

Figure 14. von Mises stresses of corroded pipeline $\left(t=6 \mathrm{~mm} ; t_{1}=0.8 t ; Q=60^{\circ}\right)$ for different bedding depths $\left(B_{\mathrm{H}}\right)$ 
To determine which bedding configuration will be suitable for protective measure in terms of providing both structural improvement to the damaged pipeline wall and reducing installation cost, further parametric study were conducted using the proposed damaged model. In addition, the pipe defect configuration is based on the worst case condition. Here, pipe wall thickness $t$ $=6 \mathrm{~mm}$, defect depth $t_{1}=0.8 \mathrm{t}$ and $Q=60$ degrees. The bedding depth parameters $B_{\mathrm{H}} 87.5 \mathrm{~mm}$, $175 \mathrm{~mm}, 350 \mathrm{~mm}, 700 \mathrm{~mm}$ and $1050 \mathrm{~mm}$ respectively, are used.
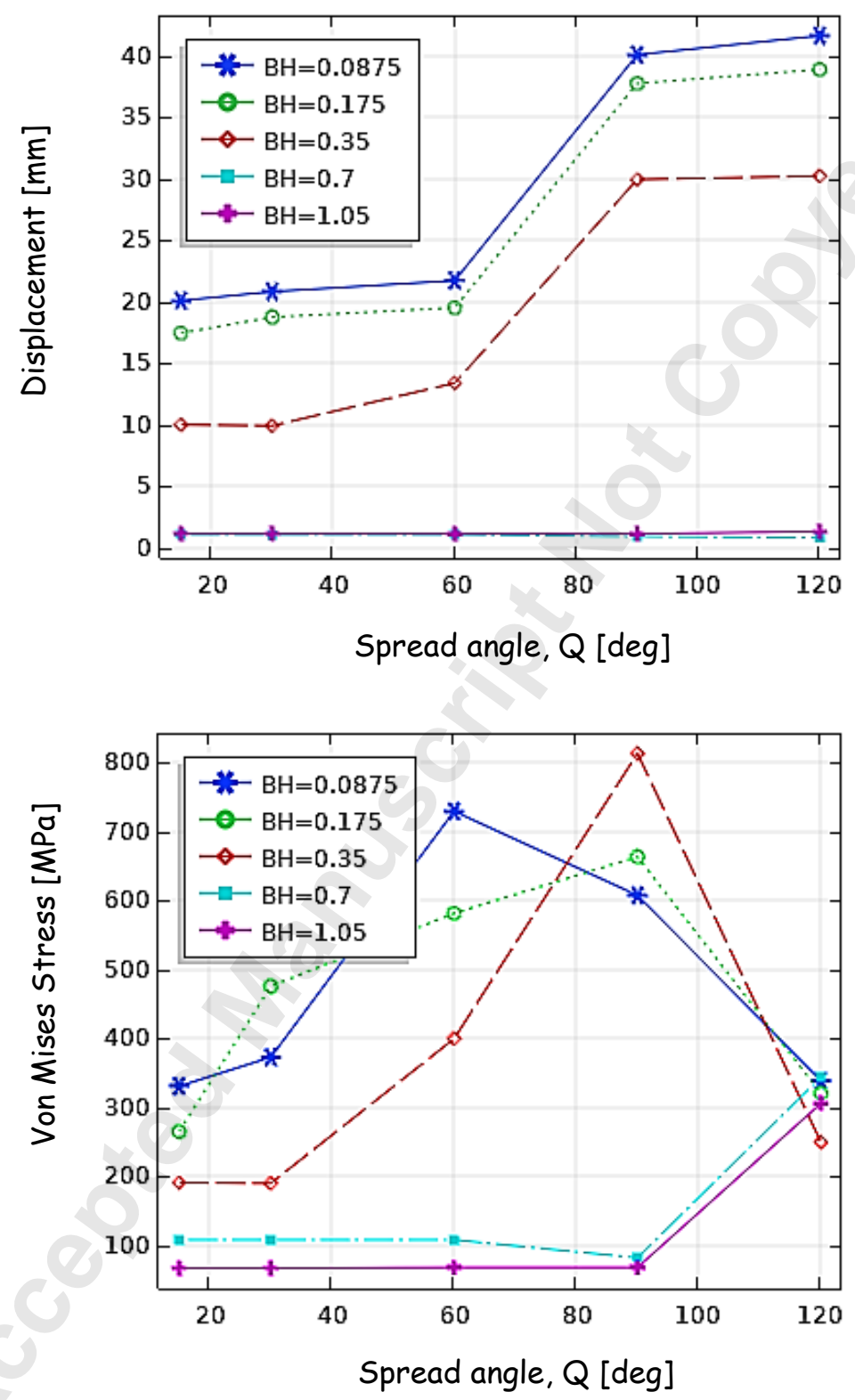

(b)

Figure 15. Pipeline response under different bedding depth, $B_{\mathrm{H}}$ w.r.t defect spread angle, $Q$ for $t=23.83 \mathrm{~mm}$ and $t_{1}=0.8 t$ : (a) Displacement and (b) von Mises stress 
The responses of the damaged pipe in terms of the deflection and von Mises stresses are presented in Figs. 13 and 14. These results show different stages of protective bedding depths for the case of 60 degrees defect spread angle and how the damaged pipeline could be supported. From these two analyses, it is clear that the bedding depth provides added reinforcement to the damaged pipe. The pipe deflection tends to reduce with corresponding increase in bedding depth boundary and is able to provide a safe deflection level at 0.7 and 1.05 $\mathrm{m}$ depths. However, the stress level tends to increase with increasing depth up to $0.35 \mathrm{~m}$ and decreases afterwards. The von Mises stress are experienced internally and are within the yield limit of $411 \mathrm{MPa}$ which is assumed to be within the pipeline tolerable limits of elastic deformation.

Further studies on effect of different bedding profiles on damaged pipe displacement and von Mises stress levels are demonstrated in Figure 15 (a) and (b) in relation to defect location for $t$ $=23.83 \mathrm{~mm}$, which represents a typical thick walled flexible pipe scenario. From Fig. 15(a), it can be seen that for thicker pipe sections, displacement also increases along increase in defect spread angle. This is reduced with increasing depth of protection from the bedding boundaries. Out of five cases studied, two bedding depth configurations (i.e. at depth of $0.7 \mathrm{~m}$ and $1.05 \mathrm{~m}$ ) actually provide protection for the deeply corroded pipe section way below the tolerable deflection limit of $28 \mathrm{~mm}$. Other configurations which are less expensive to construct (i.e. at depth of $0.0875 \mathrm{~m}, 0.175 \mathrm{~m}$ and 0.35 could only provide adequate protection from excessive deflections for pipe sections with defect spread angles below 60 degrees. The plot of the von Mises stress from Fig. 15(b) also indicate the structure could be well secured within its elastic range with the provision of adequate bedding depth. However all three bedding depth configurations (i.e. $0.0875 \mathrm{~m}, 0.175 \mathrm{~m}$ and $0.35 \mathrm{~m}$ ) experience sharp increase in stress concentration and above the yield limit at some stage of the defect growth. Therefore based on all the cases considered, the most sustainable configuration would be at bed depths of $0.7 \mathrm{~m}$ and $1.05 \mathrm{~m}$ as these boundaries offers the required safety against excessive deflection and plastic deformation needed to protect the pipeline for the long duration. 


\section{CONCLUSIONS}

In this study, numerical modelling has been conducted to investigate failure of vertically loaded buried steel pipeline section with uniform internal corrosion. The pipe failure is quantified in terms of excessive deflection and plastic deformation. For this purpose a series of 3dimensional FE models were developed. The effect of two main defect parameters, depth and spread angle were evaluated considering worst-case pipeline damage conditions. Subsequently, the results from the parametric analysis provide details previously limited in the literature and offer an understanding into the unpredictability behaviour of buried infrastructures. The findings from this work lead to the following conclusions.

1. Buried pipes with thicker wall sections perform better than their slender counterparts for both intact and damaged conditions. Failure mechanism is controlled by excessive deflection and plastic deformation.

2. An increase in spread angle may increase deflection linearly but not necessarily the wall stress. The wall stresses are found to be stable at spread angles 15, 30 and 120 degrees and are unstable at locations of 60 and 90 degrees.

3. A bedding protective measure was proposed to accommodate different stages of internal corrosion damage. The proposed protective bedding configuration is predicted to provide adequate long time protection when the pipes section maximum deflection is less than $2 \%$ of the outside diameter and von Mises stress is below the yield strength.

4. The protective bed configuration is found to offer most reliable cover for long time protection at bedding depth of $0.7 \mathrm{~m}$, which corresponds to half the outside pipe diameter.

\section{REFERENCES}

1. Tee, K.F., Ebenuwa, A.U., and Zhang, Y. (2018) Fuzzy-based robustness assessment of buried pipelines, Journal of Pipeline Systems Engineering and Practice, ASCE, 9(1), 06017007.

2. Armaghani, D. J, Faizi, K., Hajihassani, M., Tonnizam Mohamad, E. and Nazir, R. (2015) Effects of soil reinforcement on uplift resistance of buried pipeline, Measurement, 64, pp. $57-63$.

3. González, O., Fraile, A. and Hermanns, L. (2015) A numerical and semi-analytical comparison for structural analysis of fault-crossing pipelines, Comptes Rendus - 
Mecanique, 343(7-8), pp. 397-409.

4. Rahman, M. A. and Taniyama, H. (2015) Analysis of a buried pipeline subjected to fault displacement: A DEM and FEM study, Soil Dynamics and Earthquake Engineering, 71, pp. 49-62.

5. Uckan, E., Akbas, B., Shen, J., Rou, W., Paolacci, F. and O’Rourke, M. (2015) A simplified analysis model for determining the seismic response of buried steel pipes at strike-slip fault crossings, Soil Dynamics and Earthquake Engineering, 75, pp. 55-65.

6. Ebenuwa, A.U., Tee, K.F. and Zhang, Y. (2016) Structural robustness assessment of corroded buried pipes, in the WIT Transactions on the Built Environment, 166, Edited by S.Hernandaz, C.A.Brebbia and W.P. de Wilde, WIT Press, pp. 81-92.

7. Pesinis, K. and Tee, K.F. (2018) Bayesian updating of stochastic process-based models for corroding gas pipelines based on imperfect inspection information, in the Safety and Reliability - Safe Societies in a Changing World, Edited by S.Haugen et al, published by Taylor and Francis Group, pp. 2219-2226.

8. Shafiee, M. \& Ayudiani P.S. (2015) Development of a risk-based integrity model for offshore energy infrastructures - application to oil and gas pipelines, International Journal of Process Systems Engineering, 3(4), pp. 211-231.

9. Pesinis, K. and Tee, K.F. (2017) Statistical model and structural reliability analysis for onshore gas transmission pipelines, Engineering Failure Analysis, 82, pp. 1-15.

10. Ebenuwa, A.U., Tee, K.F. (2019) Reliability estimation of buried steel pipes subjected to seismic effect, Transportation Geotechnics, 20, 100242.

11. Nanan, K. (2018) The 8 Most Common Forms of Metal Corrosion, Corrosionpedia.

12. Tee, K.F., and Pesinis, K. (2017) Reliability prediction for corroding natural gas pipelines, Tunnelling and Underground Space Technology, 65, pp. 91-105.

13. Khan, L.R. and Tee, K.F. (2016) Risk-cost optimization of buried pipelines using subset simulation, Journal of Infrastructure Systems, ASCE, 22(2), 04016001.

14. Cronin, D. S. (2000) Assessment of Corrosion Defects in Pipelines, PhD Thesis, University of Waterloo.

15. Xu, L. (2013) Assessment of corrosion defects on high-strength steel pipelines, University of Alberta.

16. Ebenuwa, A.U., Tee, K.F. (2019) Fuzzy-based optimised subset simulation for reliability analysis of engineering structures, Structure and Infrastructure Engineering, 15(3), pp. 413-425.

17. Bueno, A. H. S., Moreira, E. D. and Gomes, J. A. C. P. (2014) Evaluation of stress corrosion 
cracking and hydrogen embrittlement in an API grade steel, Engineering Failure Analysis, 36, pp. 423-431.

18. Motta, R. S., Cabral, H. L. D., Afonso, S. M. B., Willmersdorf, R. B., Bouchonneau, N., Lyra, P. R. M. and de Andrade, E. Q. (2017) Comparative studies for failure pressure prediction of corroded pipelines, Engineering Failure Analysis, 81, pp. 178-192.

19. Oh, C. S., Kim, N. H., Kim, Y. J., Baek, J. H., Kim, Y. P. and Kim, W. S. (2011) A finite element ductile failure simulation method using stress-modified fracture strain model, Engineering Fracture Mechanics, 78(1), pp. 124-137.

20. Al-Owaisi, S. S., Becker, A. A. and Sun, W. (2016) Analysis of shape and location effects of closely spaced metal loss defects in pressurised pipes, Engineering Failure Analysis, 68, pp. 172-186.

21. Xu, W. Z., Li, C. B., Choung, J. and Lee, J. M. (2017) Corroded pipeline failure analysis using artificial neural network scheme, Advances in Engineering Software, 112, pp. 255266.

22. Pesinis, K. and Tee, K.F. (2018) Bayesian analysis of small probability incidents for corroding energy pipelines, Engineering Structures, 165, pp. 264-277.

23. Watkins, R.K. and Loren, R.A. (2000) Structural Mechanics of Buried Pipes, CRC Press, 444 pages, Boca Raton, Florida.

24. Katona, M., Forrest, J., Odello, R. and Allgood, J. (1976) CANDE-a modern approach for the structural design and analysis of buried culverts. Federal Highway Administration, Office of Research and Development, report no. S0648 No. FHWA RD-77-5, Washington D.C. USA.

25. Duncan, J. M., Byrne, P., Wong, K. S. and Mabry, P. (1980) Strength, Stress-Strain and Bulk Modulus Parameters for Finite Element Analysis of Stresses and Movements in Soil Masses, University of California, report no. UCB/GT/80-01, Berkeley, California, USA.

26. Leonards, G. A., Wu, T. H. and Juang C.H. (1981) Predicting Performance of Buried Conduits, FHWA/IN/JHRP-81/03. Joint Highway Research Project, Indiana Department of Transportation and Purdue University, West Lafayette, Indiana.

27. Nyby, B. (1981) Finite Element Analysis of Soil-Structure Interaction, Ph.D. Thesis, Utah State University, Logan, USA.

28. Sharp, K.D, Anderson, L.R, Moser, A.P and Warner, M.J. (1984) Applications of finite element analysis of FRP pipe performance, Buried Structures Laboratory, Utah State University, Logan, USA.

29. El-taher, M. and Moore, I. D. (2008) Finite Element Study of Stability of Corroded Metal 
Culverts, Transportation Research Board, pp. 157-166.

30. Lui, P., Zhang, B. and Shi, P. (2010) Failure analysis of natural gas buried X65 steel pipeline under deflection load using finite element method, Materials and Design, 31, pp. 1384-1391.

31. Vettorelo, P.V., Moreno, F.M. and Claria, J.J. (2016) Modelling of Geosynthetic Reinforced Buried Flexible Pipes, In: 3rd Pan American Conference on Geosynthetics, Miami, USA, 10-13 April 2016, pp. 1808-1816.

32. Yu, J., Wang, H., Fan, Z. and Yu, Y. (2017) Computation of plastic collapse capacity of 2D ring with random pitting corrosion defect, Thin-Walled Structures, 119, pp. 727-736.

33. Alzabeebee, S., Chapman, D. N. and Faramarzi, A. (2018) A comparative study of the response of buried pipes under static and moving loads, Transportation Geotechnics, 15, pp. 39-46.

34. Alzabeebee, S., Chapman, D. N. and Faramarzi, A. (2018) Innovative approach to determine the minimum wall thickness of flexible buried pipes, Geomechaics and Engineering, 15(2), pp. 755-767.

35. Hegde, A. M. and Sitharam, T. G. (2015) Experimental and numerical studies on protection of buried pipelines and underground utilities using geocells, Geotextiles and Geomembranes, 43(5), pp. 372-381.

36. Zhang, J., Liang, Z., Feng, D., Zhang, C., Xia, C. and Tu, Y. (2016) Response of the buried steel pipeline caused by perilous rock impact : Parametric study, Journal of Loss Prevention in the Process Industries, 43, pp. 385-396.

37. Srivastava, A. and Babu, G. L. S. (2011) Deflection and buckling of buried flexible pipesoil system in a spatially variable soil profile, Geomechaics and Engineering, 3(3), pp. $169-188$.

38. Alzabeebee, S., Jefferson, I., Faramarzi, A. and Chapman, D. (2016) The response of buried pipes to UK standard traffic loading, Geotechnical Engineering, 170(1), pp. 1-13.

39. Athmani, A., Khemis, A., Hacene-Chaouche, A., Tee, K. F., Ferreira, T. M. and Vicente, R. (2019) Buckling uncertainty analysis for steel pipelines buried in elastic soil using FOSM and MCS methods, International Journal of Steel Structures, 19(2), pp. 381-397.

40. Watkins, R.K. and Spangler, M.G. (1958) Some characteristics of the modulus of passive resistance of soil: A study in similitude, Highway Research Board Proceedings 37, pp. $576-583$.

41. Burns, J.Q. and Richards, R.M. (1964) Attenuation of Stresses for Buried Cylinders, In: Proceedings of the Symposium on Soil Structure Interaction, University of Arizona, pp. 
$378-392$.

42. AASHTO (1994) AASHTO LRFD Bridge Design Specifications, American Association of State Highway and Transportation Officials, 1st edition, Washington, D.C., USA.

43. Eagle, J. M. (2009) Depth of Burial For PVC Pipe, Technical Bulletin, pp. 1-4.

44. Stephenson, D. (1989) Pipeline design for Water Engineers, Volume 40, 3rd edition, Elsevier Scientific Publishing Company, New York, USA.

45. Moser, A. and Folkman, S. (2008) Buried Pipe Design, 3rd edition, McGraw Hill, New York, USA.

46. Tee, K.F., Khan, L.R. and Coolen-Maturi, T. (2015) Application of receiver operating characteristic curve for pipeline reliability analysis, Journal of Risk and Reliability, Proceedings of the Institution of Mechanical Engineers, Part O, 229(3), pp. 181-192.

47. Spangler, M.G. (1941) The structural design of flexible culverts, Bulletin 153, Iowa Engineering Experiment Station, Iowa State College of Agriculture and Mechanic Arts, 84 pages.

48. BS EN 1295-1 (1997) Structural design of buried pipelines under various conditions of loading Part 1. General requirements, BSI Group, UK.

49. Zhang, J., Liang, Z. and Zhao, G. (2016) Mechanical behaviour analysis of a buried steel pipeline under ground overload, Engineering Failure Analysis, 63, pp. 131-145.

50. Khemis, A., Hacene-Chaouche, A., Athmani, A. and Tee, K.F. (2016) Uncertainty effects of soil and structural properties on the buckling of flexible pipes shallowly buried in Winkler foundation, Structural Engineering and Mechanics, 59(4), pp. 739-759.

51. Masada, T. (2000) Modified Iowa formula for vertical deflection of buried flexible pipe, Transp. Eng., 125(5), pp. 440-446.

52. Ryu, D. M., Wang, L., Kim, S. K. and Lee, J. M. (2017) Comparative study on deformation and mechanical behavior of corroded pipe: Part I-Numerical simulation and experimental investigation under impact load, International Journal of Naval Architecture and Ocean Engineering, 9(5), pp. 509-524. 